\title{
Dual roles of SAMHD1 in tumor development and chemoresistance to anticancer drugs (Review)
}

\author{
ZHANGMING $\mathrm{CHEN}^{1 *}, \mathrm{JIE} \mathrm{HU}^{1,2^{*}}$, SONGCHENG YING ${ }^{2}$ and AMAN XU ${ }^{1}$ \\ ${ }^{1}$ Department of General Surgery, The Fourth Affiliated Hospital of Anhui Medical University, Hefei, Anhui 230001;
${ }^{2}$ Department of Immunology, School of Basic Medical Sciences, Anhui Medical University, Hefei, Anhui 230032, P.R. China
}

Received October 14, 2020; Accepted March 10, 2021

DOI: $10.3892 / \mathrm{ol} .2021 .12712$

\begin{abstract}
Human sterile alpha motif and HD-domaincontaining protein 1 (SAMHD1) has been identified as a GTP or dGTP-dependent deoxynucleotide triphosphohydrolase (dNTPase) and acts as an antiviral factor against certain retroviruses and DNA viruses. Genetic mutation in SAMHD1 causes the inflammatory Aicardi-Goutières Syndrome and abnormal intracellular deoxyribonucleoside triphosphates (dNTPs) pool. At present, the role of SAMHD1 in numerous types of cancer, such as chronic lymphocytic leukemia, lung cancer and colorectal cancer, is highly studied. Furthermore, it has been found that methylation, acetylation and phosphorylation are involved in the regulation of SAMHD1 expression, and that genetic mutations can cause changes in its activities, including dNTPase activity, long interspersed element type 1 (LINE-1) suppression and DNA damage repair, which could lead to uncontrolled cell cycle progression and cancer development. In addition, SAMHD1 has been reported to have a negative regulatory role in the chemosensitivity to anticancer drugs through its dNTPase activity. The present review aimed to summarize the regulation of SAMHD1 expression in cancer and its function in tumor growth and chemotherapy sensitivity, and discussed controversial points and future directions.
\end{abstract}

Correspondence to: Professor Aman Xu, Department of General Surgery, The Fourth Affiliated Hospital of Anhui Medical University, 100 HuaiHai Avenue, Hefei, Anhui 230001, P.R. China E-mail: xamhwx@163.com

Professor Songcheng Ying, Department of Immunology, School of Basic Medical Sciences, Anhui Medical University, 81 Meishan Avenue, Hefei, Anhui 230032, P.R. China

E-mail: yingsc@ahmu.edu.cn

*Contributed equally

Key words: sterile $\alpha$ motif and HD-domain-containing protein 1, cancer, cell cycle, DNA damage repair, chemosensitivity

\section{Contents}

1. Introduction

2. Role of methylation, acetylation and phosphorylation in the regulation of SAMHD1 expression in cancer

3. SAMHD1 inhibits the development of numerous types of tumor

4. SAMHD1 is a negative regulator of nucleotide analogs in vitro and in vivo.

5. Future directions and conclusion

\section{Introduction}

Human sterile $\alpha$ motif and HD domain-containing protein 1 (SAMHD1), also known as dendritic cell derived IFN- $\gamma$ induced protein, was first identified as interferon (IFN) $-\gamma$ induced protein in human dendritic cells (1). SAMHD1 has an N-terminal nuclear localization signal (1-150), which contains the transferable sequence $\left({ }^{11} \mathrm{KRPR}^{14}\right)(2)$, an $\mathrm{N}$-terminal SAM domain, which interacts with proteins, and an HD domain, which is responsible for the hydrolysis of deoxyribonucleoside triphosphates (dNTPs) (3). SAMHD1 is widely expressed in most human tissues and cell lines (1). Rice et al (4) reported 14 mutations in exons of SAMHD1 gene in patients with Aicardi-Goutières syndrome (AGS), resulting in alterations of the amino acid sequence (4). Mass spectrometry results have demonstrated that SAMHD1 interacts with Vpx, which induces the degradation of SAMHD1 via the ubiquitin-proteasome pathway (5). Previous studies have reported that SAMHD1 can block the replication of human immunodeficiency virus type 1 (HIV-1) by hydrolyzing dNTPs, which depletes the pool of dNTPs available for reverse transcription essential to DNA replication of HIV-1 (6), hepatitis B virus (HBV) $(7,8)$ and herpes simplex virus 1 (9).

The maintenance of an appropriate intracellular dNTPs pool is essential for cell cycle progression, and an imbalance in the pool of dNTPs can enhance mutagenesis and DNA replication, resulting in dysregulation of the cell cycle (10). SAMHD1 is the first dNTP triphosphohydrolase (dNTPase) discovered in mammalian cells and is crucial in maintaining the homeostasis of intracellular dNTPs (6). dGTP- $\mathrm{Mg}^{2+}$-dGTP binding at the allosteric site promotes the tetramerization of SAMHD1 protein, leading to the formation of catalytically 
active enzymes (11). A previous study demonstrated that SAMHD1 has an essential role in regulating the cell cycle in quiescent and cycling cells via regulation of the intracellular concentration of dNTPs (12). In addition, genetic mutations of SAMHD1 have been discovered in several types of cancer, including chronic lymphocytic leukemia (CLL) (13), lung cancer (14) and colorectal cancer (15). Methylation at the promoter of SAMHD1 has been demonstrated to decrease its mRNA and protein expression (14), and the functions of SAMHD1 are affected by acetylation (16) and phosphorylation (17). In particular, SAMHD1 is involved in DNA damage repair (DDR) (18), long interspersed element type 1 (LINE-1) suppression $(19,20)$ and chemosensitivity to anticancer drugs $(21,22)$. In addition, genetic mutations of SAMHD1 contribute to amino acid changes, which in part impair its functions $(11,15)$.

The present review aimed to summarize the underlying mechanisms of SAMHD1 in cancer development and chemosensitivity to anticancer drugs, and discussed numerous controversial hypotheses.

\section{Role of methylation, acetylation and phosphorylation in the regulation of SAMHD1 expression in cancer}

The transcriptional regulation of SAMHD1 is the result of methylation of its promoter. This has been observed in several types of tumor tissue and cell line. Human SAMHD1 is expressed at different levels in cell lines and tissues (1). de Silva et al (23) reported that the protein expression of SAMHD1 is correlated with its mRNA expression level in THP-1 and $\mathrm{CD} 4^{+} \mathrm{T}$ cells. In peripheral blood mononuclear cells from patients with cutaneous T-cell lymphoma (CTCL), both the mRNA and protein expression levels are significantly lower compared with those in healthy donors (24), which was also observed in lung cancer tissues compared with adjacent normal tissues (14). The different expression levels of SAMHD1 mRNA and protein in various types of cancer are summarized in Table I. The level of methylation has also been demonstrated to be inversely associated with the expression of SAMHD1 in 466 skin cutaneous melanoma samples from The Cancer Genome Atlas (TCGA) (25). Taken together, these findings indicate that epigenetic regulation plays an important role in the protein expression of SAMHD1. Results from methylation-specific PCR demonstrated that the SAMHD1 promoter is methylated in lung adenocarcinoma tissues compared with adjacent normal tissues (14). Furthermore, in patients with CTCL, methylated SAMHD1 has also been observed whereas it was absent in healthy donors (24). The DNA methylation inhibitor 5-aza-2'-deoxycytidine (5-AzadC) has been reported to increase the mRNA and protein expression levels of SAMHD1 in the lung cancer cell line A549 (14), and Jurkat and Sup-T1 cells (acute T-cell leukemia) (24). Conversely, the promoter of SAMHD1 has been demonstrated to be in an unmethylated state in THP-1 cells (23) and SAMHD1 protein expression does not increase following treatment with 5-AzadC. Furthermore, decitabine, which is a DNA methyltransferase inhibitor, has been demonstrated to be a substrate of SAMHD1, and its anticancer effect in acute myelocytic leukemia (AML) was found to be dependent of SAMHD1 protein expression (26). For other tumors characterized by methylation of the SAMHD1 promoter, further investigation is required to determine whether SAMHD1 could have a two-sided effect on chemotherapy with decitabine.

Acetylation has been reported to be involved in the post-transcriptional regulation of SAMHD1 expression. Trichostatin A (TSA), a histone deacetylase inhibitor, can increase the mRNA and protein expression of SAMHD1 in Jurkat and Sup-T1 cells (23). Lee et al (16) reported that SAMHD1 is acetylated at the K405 site via arrest defective protein 1 (ARD1), which leads to enhanced dNTPase activity (16). Furthermore, SAMHD1 and ARD1 protein expression has been found to be upregulated in hepatoma tissues compared with non-tumor tissues, which indicates that SAMHD1 acetylated by ARD1 may participate in tumorigenesis (16). However, the K580 residue of SAMHD1, which is another acetylated site, could not be acetylated by ARD1 in vitro (16). In particular, 5-AzadC and TSA were found to notably increase the mRNA expression of SAMHD1; however, only a slight increase in SAMHD1 protein expression was observed in Jurkat and Sup-T1 cells (23). Subsequently, besides methylation and acetylation, another regulatory mechanism may exist in SAMHD1 transcription or translation.

Phosphorylated SAMHD1 at the Thr592 site was first reported in 2013 (27). Another study revealed that SAMHD1 protein was phosphorylated at four major sites, including Thr592, Thr21, Ser6 and Ser33 (28). White et al (27) demonstrated that the expression of phosphorylated SAMHD1 at Ser33 site is equal in cycling and non-cycling U937 cells (27). It was reported that Thr592 has the largest effect on SAMHD1 phosphorylation, whereas mutation of Ser6 does not appear to affect SAMHD1 phosphorylation (28). The $\mathrm{S}$ phase is initiated by cyclin E/cyclin-dependent kinase (CDK) 2, cyclin A/CDK1 and cyclin $\mathrm{A} / \mathrm{CDK} 2$ complexes, which are essential for the transition from $S$ phase to $M$ phase (29). The (S/T)PX $(K / R)$ is a well-defined consensus sequence for the phosphorylation site in the amino acid sequence of a CDK substrate (30). SAMHD1 wild-type protein contains a sequence ${ }^{592} \mathrm{TPQK}^{595}$, which could be the substrate for CDKs. Further in vitro experiments have shown that the C-terminal domain of SAMHD1 is the target sequence for the cyclin A2/CDK1 complex, which could not phosphorylate SAMHD1 mutant at the 592 site (Fig. 1) $(31,32$ ). Furthermore, the expression of SAMHD1 and phosphorylated SAMHD1 differed in the S phase compared with other cell cycle phases (33), indicating that phosphorylation modification of SAMHD1 by cyclin-CDKs complex is critical for transition of G1/G0 to $S$ phase. In addition, phosphorylation of SAMHD1 can also be suppressed by the CDK2 inhibitor II in hepatoma cells (34). Palbociclib can also significantly decrease SAMHD1 phosphorylation in monocyte-derived macrophages and $\mathrm{CD} 4^{+} \mathrm{T}$ lymphocytes by downregulating the CDK6 downstream CDK2 phosphorylation at Thr160 $(35,36)$. Furthermore, a previous study revealed that phosphorylated SAMHD1 appears at the G1/S border and lasts until mitosis, and could interact directly with cyclin E and cyclin A2 at its $\mathrm{C}$ terminus end (17). However, it remains unclear whether SAMHD1 mutations at the $\mathrm{C}$ terminus could attenuate the anticancer effect of CDK inhibitors. Depletion of SAMHD1 promotes G1/G0 phase arrest and cell senescence in HeLa cells, which is associated with an increased expression of p21 (32). Conversely, p21 has been demonstrated to have no 


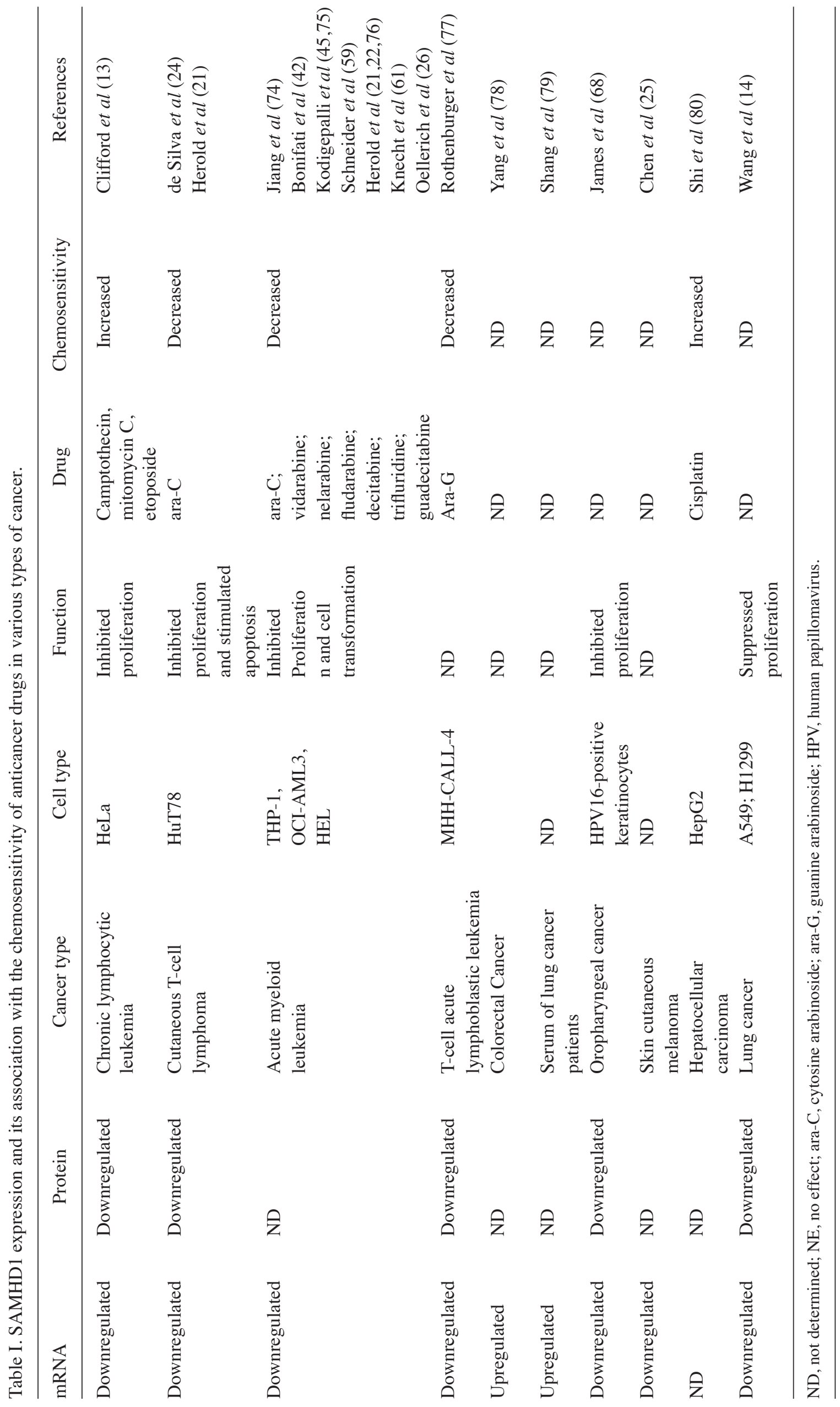




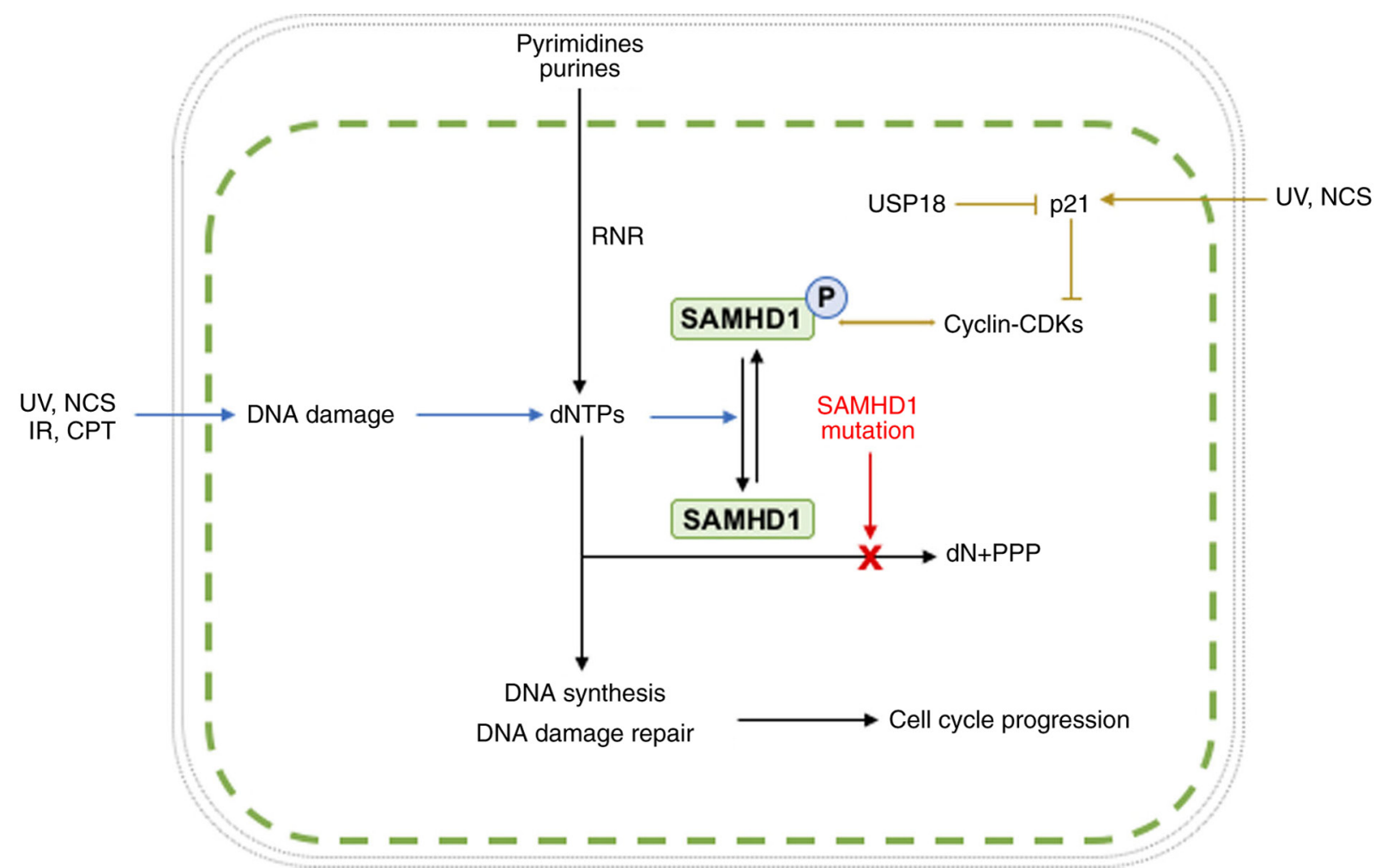

Figure 1. Role of SAMHD1 and mutants in DNA damage repair and cell cycle progression. dNTPs have key roles in DNA replication and damage repair. DNA damage caused by UV or NCS increases dNTP in the cell cycle. Cyclin/CDK complexes interact with SAMHD1 and promote SAMHD1 phosphorylation, which is suppressed by CDK inhibition (p21). In addition, UV and NCS increase the expression of p21, leading to dephosphorylation of SAMHD1 and increased dNTPase activity. However, USP18 suppresses the role of p21 in regulating SAMHD1 dephosphorylation. Light orange indicates homologous recombination. UV, ultraviolet radiation; NCS, neocarzinostatin; RNR, ribonucleotide reductase; USP18, ubiquitin-like specific protease 18; MMR, mismatch repair; IR, ionizing radiation; CPT, camptothecin; SAMHD1, sterile a motif and HD domain-containing protein 1; dNTP, deoxyribonucleoside triphosphate; dNTPase, dNTP triphosphohydrolase.

effect on the expression of total SAMHD1 protein (37) but can reverse CDK-induced phosphorylation of SAMHD1 by taking on the role of CDK inhibitor (Fig. 1) (38). Ubiquitin-like specific protease 18 (USP18) suppresses the expression of p21 protein, leading to phosphorylation of SAMHD1 (Fig. 1) (39). IFN- $\beta$ can also inhibit the phosphorylation of SAMHD1, but not decrease total SAMHD1 expression (39). Protein phosphatase 2 (PP2A)-B55 $\alpha$ holoenzymes can interact with and dephosphorylate SAMHD1 at T592 in cycling cells (40). Repression of CDK1/2 via aryl hydrocarbon receptor activation has been demonstrated to be responsible for SAMHD1-mediated hydrolysis of dNTPs in macrophages (41). Taken together, these results suggested that SAMHD1 phosphorylation is regulated by CDKs-interacting proteins.

\section{SAMHD1 inhibits the development of numerous types of tumor}

SAMHDl can inhibit cancer development through its dNTPase activity. In 2011, SAMHD1 was identified as a dNTPase that hydrolyzes cellular dNTPs (6). The expression of SAMHD1 in quiescent fibroblasts was found to be higher than that in cycling fibroblasts, and inversely associated with the percentage of lung fibroblasts in the S phase (12). Bonifati et al (42) reported that, compared with control groups, SAMHD1 knockdown can increase the concentration of dNTPs in THP-1 cells, enhance cell proliferation and decrease cell apoptosis (42). Furthermore, overexpression of SAMHD1 reduces the proliferation of HeLa (cervical cancer), A549 (lung cancer) and HuT78 (CTCL) cells $(13,14,43)$, which is accompanied by increased cell apoptosis via activation of the caspase- 3 pathway (43). Mutations of SAMHD1 gene at critical sites can cause changes in dNTPase activity (Fig. 1), which is summarized in Table II. Welbourn et al (44) discovered that SAMHD1 mutant H206A/D207A is disabled to hydrolyze the intracellular dNTPs in HeLa cells (44). Furthermore, mutations of SAMHD1 at catalysis-related sites, including K312A, Y315A, R366A, H370A and Y374G, lead to decreased dNTPase activity (11). Eight heterozygous mutations of SAMHD1 were identified in colorectal cancer according to TCGA database, including D497Y, V133I(X2), A388V, A525T, R366H, K596fs and A388T (15). The dNTPase activity of the mutations V133I, A338T and R366H is weakened to various degrees and is completely lost in the D497Y mutation compared with the wild-type SAMHD1 protein (15). However, the growth rate of THP-1 xenograft tumors following SAMHD1 knockdown was reported to be decreased compared with the control group in vivo, which differs from the in vitro findings (45).

SAMHD1 can suppress LINE-1 retrotransposon in various types of cancer. LINE-1 is the only active autonomous retrotransposon in the human genome and has non-long terminal repeats, which can encode its mRNA and two open reading frame (ORF) proteins, ORF1p and ORF2p $(46,47)$. 
Table II. The variants of SAMHD1 and its role to chemosensitivity of drugs in cancers.

\begin{tabular}{|c|c|c|c|c|c|}
\hline Mutants & Cancer tissues & Function & Drug & Chemosensitivity & References \\
\hline Insertion in exon4 & $\begin{array}{l}\text { Hepatocellular } \\
\text { carcinoma }\end{array}$ & ND & Cisplatin & Increased & Shi et al (80) \\
\hline $\begin{array}{l}\text { Deletions of exons8-9, } \\
13 \text { and } 14\end{array}$ & $\begin{array}{l}\text { Hepatocellular } \\
\text { carcinoma }\end{array}$ & ND & Cisplatin & NE & Shi et al (80) \\
\hline $\begin{array}{l}\text { F545L, M1K, C522X, } \\
\text { Y155C, L431S, D501Y, } \\
\text { R371H, R145Q, W572X, } \\
\text { L493R, H206R, I201N, } \\
\text { E355K, R145X, T365P, } \\
\text { I300L, P158S, D16Y, } \\
\text { L244F, R290C, R451C, } \\
\text { R451C, V500G }\end{array}$ & $\begin{array}{l}\text { Chronic } \\
\text { lymphocytic } \\
\text { leukemia }\end{array}$ & ND & ND & ND & Clifford et al (13) \\
\hline c. $1411-2 A>G$ & $\begin{array}{l}\text { Cutaneous } \\
\text { T-cell } \\
\text { lymphoma }\end{array}$ & ND & ND & ND & Merati et al (81) \\
\hline $\begin{array}{l}\text { c.646_647delAT } \\
\text { c. } 299 \mathrm{~T}>\mathrm{C} \\
\text { c.1352G }>\mathrm{A} \\
\text { c. } 503 \mathrm{G}>\mathrm{A} \\
\text { c. } 1562 \mathrm{~A}>\mathrm{G} \\
\text { c. } 773 \mathrm{G}>\mathrm{A} \\
\text { c.1324C }>\mathrm{T} \\
\text { c.1181A }>\mathrm{T} \\
\text { c.646_647delAT } \\
\text { c.658C }>\mathrm{T}\end{array}$ & $\begin{array}{l}\text { Chronic } \\
\text { lymphocytic } \\
\text { leukemia }\end{array}$ & ND & ND & ND & Amin et al (82) \\
\hline $\begin{array}{l}\text { D497Y, V133I(x2), } \\
\text { A388V, A525T, R366H, } \\
\text { K596fs A388T }\end{array}$ & Colon cancer & $\begin{array}{l}\text { Reduced dNTPase } \\
\text { activity }\end{array}$ & ND & ND & Rentoft et al (15) \\
\hline K484T & Gastric cancer & $\begin{array}{l}\text { Impaired interaction } \\
\text { of SAMHD1 with } \\
\text { CtBP-interacting } \\
\text { protein }\end{array}$ & Camptothecin & Decreased & Daddacha et al (55) \\
\hline rs6102991 & $\begin{array}{l}\text { Adult acute } \\
\text { myeloid } \\
\text { leukemia }\end{array}$ & $\begin{array}{l}\text { Decreased } \\
\text { SAMHD1 mRNA } \\
\text { expression } \\
\text { Decreased risk of } \\
\text { non-complete } \\
\text { remission }\end{array}$ & ND & ND & Zhu et al (83) \\
\hline
\end{tabular}

ND, not determined; NE, no effect; SAMHD1, sterile a motif and HD domain-containing protein 1.

In vitro, SAMHD1 has no effect on the expression of LINE-1 mRNA and ORF1p protein but suppresses expression of ORF2p (19). In addition, a previous study has reported more mutants of SAMHD1 protein in various types of cancer (Fig. 2) (20). Furthermore, SAMHD1 single-nucleotide polymorphisms (SNPs) at seven codon positions negatively regulate the retrotransposition of LINE-1 compared with its wild-type equivalent (48). Furthermore, SAMHD1 mutation deficiency of amino acids 162-335 attenuates the activity suppressing LINE-1; however, the mutant lacking SAM domain enhances its ability against LINE-1 (19). The enzymatically active HD domain of SAMHD1, SAM domain, is therefore crucial for the inhibition of LINE-1 retrotransposon. The dNTPase-inactive SAMHD1 mutants H206A/D207A and K288T can also inhibit the reverse transcription of LINE-1 in colon cancer $(20,48)$. Removing the nuclear localization sequence of SAMHD1 or its K11A mutants could subsequently induce its redistribution in the cytoplasm, leading to 


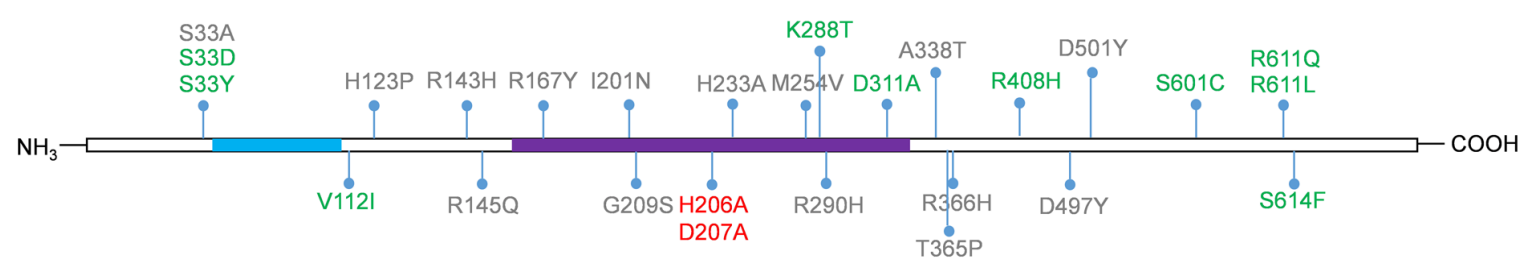

Figure 2. Cancer-related mutations of SAMHD1 and their roles in LINE-1 suppression. Gray, does not inhibit LINE-1; green, can inhibit LINE-1; red, unknown. SAMHD1, sterile a motif and HD domain-containing protein 1; LINE-1, long interspersed element type 1.

ORF2p deletion and LINE-1 suppression, but with no effect on dNTPase activity (49,50). Therefore, SAMHD1-mediated LINE-1 inhibition is independent of its dNTPase activity. In addition, the activity of SAMHD1 against LINE-1 was found to be negatively regulated by phosphorylation at Thr592 (51). Furthermore, exogenous expression of wild-type SAMHD1, instead of H233A mutant, induces abnormal distribution of ORF1p and promotes the formation of large cytoplasmic foci, which suppresses LINE-1 retrotransposon dependent of the expression of stress granule markers (Ras GTPase-activating protein-binding protein 1 and Tial cytotoxic granuleassociated RNA binding protein) (52). Interaction between SAMHD1 and ORF1p has not yet been discovered, and the underlying mechanism of SAMHD1-induced redistribution of ORF1p into stress granules requires further investigation.

SAMHDI can promote DDR following irradiation and chemotherapy. RNA ribosomal 2-mediated dNTP biosynthesis and SAMHD1-mediated dNTP hydrolysis are two different strategies used to maintain dNTP homeostasis in mammalian cells $(6,53)$ and are essential for DDR and cell survival. In addition, DNA damage also increases dNTPs pools through upregulating the activity of ribonucleotide reductase (53). Etoposide, an anticancer drug inducing DNA double-strand breaks, can also promote the dephosphorylation of SAMHD1 and the transition from G1 to G0 phase in the cell cycle, which is accompanied by a decrease in the protein expression of CDK1 (54). The cyclin A2/CDK1 complex interacts with and phosphorylates SAMHD1 at the Thr592 site (31). Subsequently, etoposide-induced dephosphorylation of SAMHD1 may result from etoposide-mediated inhibition of CDK1 when cells return from the G1 phase into the G0 phase. DNA synthesis is impeded by SAMHD1 mutants lacking the C-terminal end (618-626 residue), which is accompanied by the phosphorylation of checkpoint kinase 1 (CHK1) at Ser345 and activation of DNA damage checkpoints (33). A previous study reported that treatment with neocarzinostatin increases p21 expression, which inhibits CDK1/2, leading therefore to decreased phosphorylation of SAMHD1 (54). Dephosphorylation of SAMHD1 may thus be the result of increased p21 in DNA damage induced by ultraviolet light or neocrazinostatin (Fig. 1). Another study reported that SAMHD1 knockdown can increase U2OS (osteosarcoma), MCF7 (breast cancer) and HCT-116 (colon cancer) cell sensitivity to etoposide, camptothecin and ionizing radiation, which can be rescued by restoring the exogenous expression of SAMHD1 (55). Following treatment with camptothecin, immunofluorescence shows that SAMHD1 is colocalized with gH2A histone family member $\mathrm{X}$ and RAD51 in DNA damage sites, which are markers of DNA damage and homologous recombination, respectively (55). Furthermore, SAMHD1 is colocalized with p53-binding protein 1 foci, which is an indispensable regulatory protein involved in DDR, following camptothecin-induced DNA double-strand breaks (13). SAMHD1 has been observed at replication forks and interacts with double-strand break repair protein MRE11 exonuclease, which is followed by activation of the CHK1-ataxia telangiectasia and Rad3-related protein checkpoint and restart of the replication forks, eventually leading to acceleration of the normal fork progression, which could be restored by T592E (phosphorylation) and K312A (dNTPase-inactive) mutant of SAMHD1, but not by the T592A (non-phosphorylation) mutant (18). In addition, SAMHD1 can interact with and recruit $\mathrm{CtBP}$-interacting protein to DNA damage sites, followed by promotion of DNA end resection, which could not be rescued by the gastric cancer-related K484T mutant of SAMHD1- (55). Further experiment shows that K484T mutant has no dNTPase activity and can not hydrolyze dNTPs (55). Therefore, SAMHD1 can promote DDR in cancer cells in response to DNA double-strand break-inducing agents through a phosphorylation-dependent mechanism at the Thr592 site rather than a dNTPase-dependent mechanism.

\section{SAMHD1 is a negative regulator of nucleotide analogs in vitro and in vivo}

At present, antiviral agents are nucleotide analogs that incorporate into DNA and impede DNA synthesis in the virus replication cycle. Ballana et al (56) demonstrated for the first time that degradation of SAMHD1 via Vpx can decrease the sensitivity of thymidine analogs against HIV-1, including zidovudine and stavudine (Fig. 3). Based on the understanding of dNTPase activity of SAMHD1, dNTP-based metabolite from anticancer drugs became the focus in numerous studies on anticancer drug chemosensitivity. Mutations in SAMHD1 have been found in $9.6 \%$ of patients with relapsed or refractory CLL (57) and were demonstrated to interact with proteins and implicated in DNA double-strand breaks (13). The antimetabolite cytosine arabinoside (ara-C) blocks DNA polymerase and gets incorporated into elongated DNA in the S phase of the cell cycle, leading to reduced DNA replication and eventually cell death (58). Herold et al (21) revealed that intracellular ara-CTP, a dCTP analog, is a substrate of SAMHD1 in THP-1 and HuT-78 cells. Results from high-performance liquid-chromatography demonstrated that ara-CTP is hydrolyzed to ara-C and inorganic triphosphate by SAMHD1 in the presence of allosteric activators (59). Furthermore, it was also confirmed that clofarabine is a substrate of SAMHD1 (60). In contrast to the research by Ballana et al (56), Vpx-mediated 


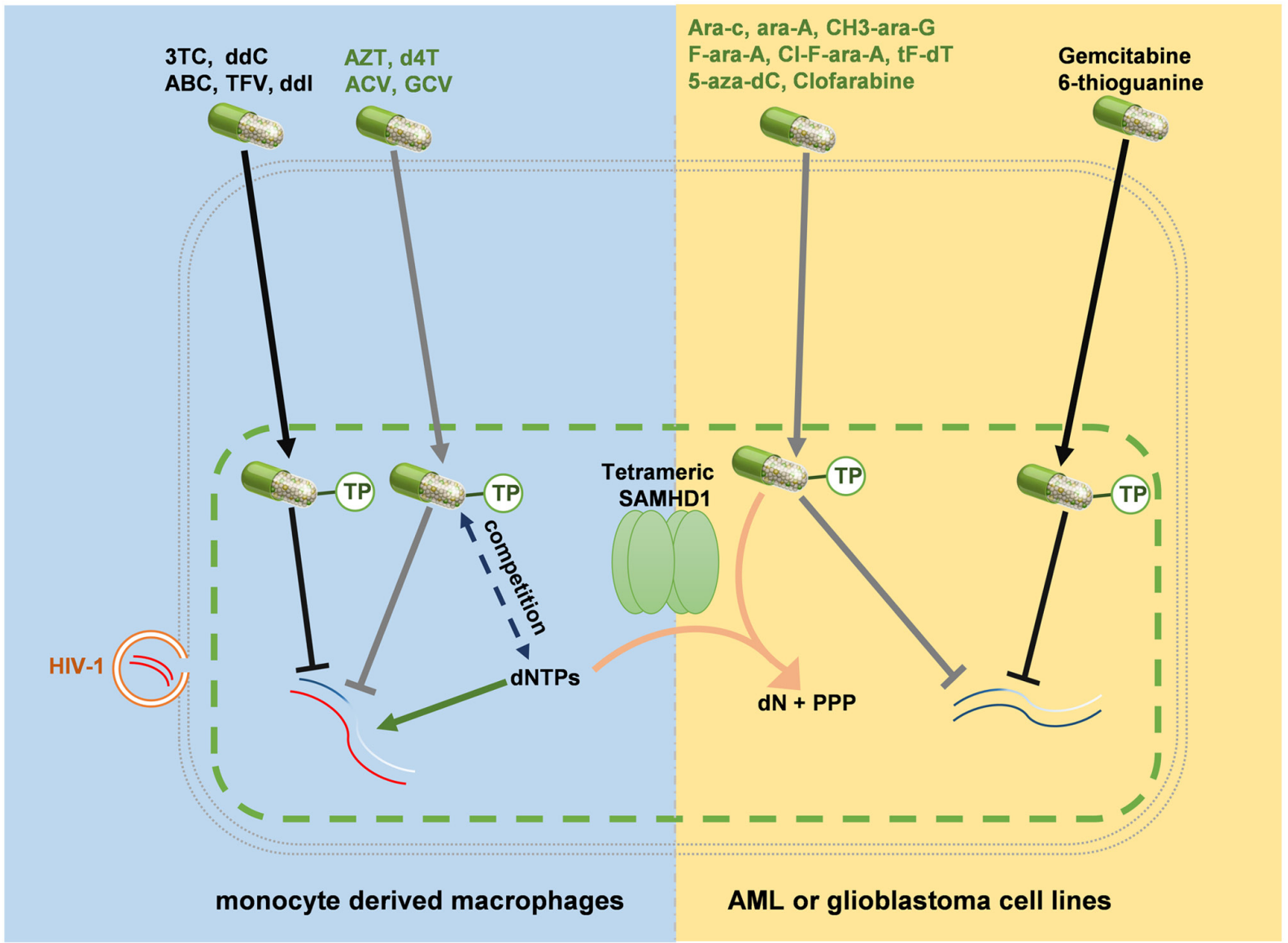

Figure 3. Sensitivity to nucleotide analog agents is regulated by SAMHD1 dNTPase activity. Nucleotide analogs, as important parts of chemotherapeutic drugs, are converted into dNTPs inside the cell and get incorporated into elongated DNA in the S phase, leading to reduced DNA replication, and eventually cell death. In monocyte-derived macrophages, the high levels of dNTPs could out-compete the nucleotide analog TPs (AZT, d4T, ACV and GCV) to incorporate into DNA, resulting in decreased efficacy of these drugs. Furthermore, lower pools of dNTPs hydrolyzed by SAMHD1 can enhance the toxicity of these nucleotide analog TPs. However, in acute myelocytic leukemia or glioblastoma cell lines, those nucleotide analog TPs (ara-C, ara-A and CH3-ara-G) can be hydrolyzed by SAMHD1, leading to the detoxification of these drugs. SAMHD1, sterile a motif and HD domain-containing protein 1; dNTP, deoxyribonucleoside triphosphate; dNTPase, dNTP triphosphohydrolase; TP, triphosphate; AZT, azidothymidine; d4t, stavudine; ACV, acyclovir; GCV, ganciclovir; ara- $\mathrm{C}$, cytosine arabinoside; ara- $\mathrm{A}$, adenine arabinoside; ara- $\mathrm{G}$, guanine arabinoside.

SAMHD1 degradation enhances the sensitivity of ara-CTP in AML and cutaneous T-cell lymphoma cells (21). Another study by Herold et al (22) reported that SAMHD1 could also hydrolyze triphosphates of other nucleotide analogs, such as vidarabine, nelarabine, fludarabin, decitabine and trifluridine (22), whereas gemcitabine and 6-thioguanine are neither substrates nor activators of SAMHD1 $(21,61)$. In a mouse model of AML, xenograft tumors with SAMHD1 knockdown presented an improved response to ara-C chemotherapy compared with those expressing SAMHD1 (21). The chemosensitivity of ara-C was also found to be negatively regulated by SAMHD1 in patient-derived AML blasts (21). In 143 patients with AML who received ara-C-based chemotherapy, patients with low SAMHD1 expression levels had higher event-free survival rates than those with high SAMHD1 expression levels (37 vs. 19\%, respectively), as well as higher 5-year overall survival rates (54 vs. 9\%, respectively) (62). Furthermore, AML cells resistant to decitabine exhibit increased SAMHD1 protein expression, which could be a result of SAMHD1 promoter demethylation (26). In addition, SAMHD1 may also be considered as a useful biomarker for predicting the response to decitabine. Apart from its role in hematological malignancies, it is also unclear whether SAMHD1 has a crucial predictive function for the efficacy of nucleotide analogs in solid tumors. Wang et al (63) first reported that U251 (glioblastoma) cells with acquired resistance to olaparib, talazoparib and simmiparib, exhibited upregulated expression levels of SAMHD1 mRNA and protein than that in parental cell lines. Furthermore, U251 cells with resistance to olaparib displayed similar cross-resistance to 5-fluorouracil, and the $\mathrm{IC}_{50}$ was increased by $>3$-fold (63). However, it remains unclear whether upregulation of SAMHD1 expression is responsible for the chemoresistance of other solid malignancies to 5-fluorouracil. The structure and biochemical framework established by Knecht et al (61) is useful to determine novel anticancer drugs that could be hydrolyzed by SAMHD1. Ribonucleotide reductase subunit R2 inhibitors (gemcitabine, hydroxyurea and triapine) occupy the AS2 site and decrease the ara-CTPase of SAMHD1, leading to enhanced chemosensitivity of AML cells to ara-C (64). Hollenbaugh et al (65) demonstrated that Y374 in the catalytic pocket of SAMHD1 could be occupied by the (2'S)-2'-methyl group of SMDU-TP, resulting in decreased dGTP hydrolysis. Further investigation is therefore needed to determine whether a combination of SAMHD1 inhibitors 
and nucleotide analogs could improve chemosensitivity in the treatment of cancer.

\section{Future directions and conclusion}

Numerous variants of SAMHD1 have been reported in hematological (13) and solid tumors, including colon cancer (15), lung cancer (14), pancreatic cancer (66) and glioblastoma (67); however, their roles in tumorigenesis and cancer development remain to be elucidated. Deletion of SAMHD1 can accelerate the proliferation of keratinocytes induced by HPV-6, which is one of the contributing factors in the development of human oropharyngeal cancer (68). In turn, HPV-6 has also been found to inhibit the endogenous expression of SAMHD1 (68). It would therefore be crucial to verify whether SAMHD1 may serve a role in other virus-related tumors, such as Epstein-Barr virus-associated gastric cancer (69) and in the development of cervical cancer due to HPV infection (70). SAMHD1 is involved in homologous recombination in response to DNA damage, which only occurs in the $\mathrm{S}$ phase $(55,71)$. However, SAMHD1 is expressed in the whole cell cycle and, thus, the function and mechanism of SAMHD1 in non-homologous recombination is worth further investigation. It is widely acknowledged that reduced dNTPase activity of SAMHD1 is the result of gene mutations and loss of expression, which leads to persistently high levels of dNTPs and abnormal cell proliferation in several types of tumor $(13,14,43)$. Numerous studies have reported that SAMHD1 can interact with cyclin/CDK complexes (30), USP18 (39) and S-phase kinase-associated protein 2 (39), which are involved in the regulation of cell proliferation $(30,39)$. However, the underlying mechanisms of SAMHD1 in the induction and regulation of tumorigenesis remain unknown, and it is hypothesized that SAMHD1 may mediate cell proliferation via dNTPase-dependent or -independent mechanisms. Previous studies have demonstrated that SAMHD1 is involved in regulating the therapeutic efficacy of nucleotide analogs in AML, which should also be investigated in solid tumors. Apart from retrospective studies, prospective cohort studies could provide more reliable evidence for this. Previous studies have also demonstrated that inhibitors of SAMHD1 dNTPase activity, including cephalosporin $\mathrm{C}$ zinc salt (72), dGTP $\alpha \mathrm{S}$, lomofungin, L-thyroxine, ergotamine, amrinone, retinoic acid, montelukast, hexestrol and sulindac (73), may be considered as potential sensitizers in anticancer therapy. In addition, modification of anticancer nucleotide analogs to eliminate SAMHD1-mediated chemoresistance may also be a useful strategy in the treatment of cancer. In conclusion, current evidence has demontrated that SAMHD1 has some dual effects in cancer, including some roles in tumor suppression and some roles in decreasing anticancer drug chemosensitivity.

\section{Acknowledgements}

Not applicable.

\section{Funding}

This work was supported by the National Natural Science Foundation of China (grant no. 81572350).

\section{Availability of data and materials}

Not applicable.

\section{Authors' contributions}

$\mathrm{ZC}$ and $\mathrm{JH}$ contributed to manuscript draft and figure design. ZC, SY and AX provided critical revision of the manuscript. Data sharing is not applicable. All authors read and approved the final manuscript.

\section{Ethics approval and consent to participate}

Not applicable.

\section{Patient consent for publication}

Not applicable.

\section{Competing interests}

The authors declare that they have no competing interests.

\section{References}

1. Li N, Zhang W and Cao X: Identification of human homologue of mouse IFN-gamma induced protein from human dendritic cells. Immunol Lett 74: 221-224, 2000.

2. Brandariz-Nuñez A, Valle-Casuso JC, White TE, Laguette N, Benkirane M, Brojatsch J and Diaz-Griffero F: Role of SAMHD1 nuclear localization in restriction of HIV-1 and SIVmac. Retrovirology 9: 49, 2012

3. Wei W, Guo H, Han X, Liu X, Zhou X, Zhang W and Yu XF: A novel DCAF1-binding motif required for Vpx-mediated degradation of nuclear SAMHD1 and Vpr-induced G2 arrest. Cell Microbiol 14: 1745-1756, 2012.

4. Rice GI, Bond J, Asipu A, Brunette RL, Manfield IW, Carr IM, Fuller JC, Jackson RM, Lamb T, Briggs TA, et al: Mutations involved in Aicardi-Goutieres syndrome implicate SAMHD1 as regulator of the innate immune response. Nat Genet 41: 829-832, 2009.

5. Laguette N, Sobhian B, Casartelli N, Ringeard M, Chable-Bessia C, Ségéral E, Yatim A, Emiliani S, Schwartz O and Benkirane M: SAMHD1 is the dendritic- and myeloid-cell-specific HIV-1 restriction factor counteracted by Vpx. Nature 474: 654-657, 2011.

6. Goldstone DC, Ennis-Adeniran V, Hedden JJ, Groom HC, Rice GI, Christodoulou E, Walker PA, Kelly G, Haire LF, Yap MW, et al: HIV-1 restriction factor SAMHD1 is a deoxynucleoside triphosphate triphosphohydrolase. Nature 480: 379-382, 2011.

7. Chen Z, Zhu M, Pan X, Zhu Y, Yan H, Jiang T, Shen Y, Dong X, Zheng N, Lu J, et al: Inhibition of Hepatitis B virus replication by SAMHD1. Biochem Biophys Res Commun 450: 1462-1468, 2014.

8. Jeong GU, Park IH, Ahn K and Ahn BY: Inhibition of hepatitis B virus replication by a dNTPase-dependent function of the host restriction factor SAMHD1. Virology 495: 71-78, 2016.

9. Kim ET, White TE, Brandariz-Núñez A, Diaz-Griffero F and Weitzman MD: SAMHD1 restricts herpes simplex virus 1 in macrophages by limiting DNA replication. J Virol 87: 12949-12956, 2013.

10. Buj R and Aird KM: Deoxyribonucleotide Triphosphate Metabolism in Cancer and Metabolic Disease. Front Endocrinol (Lausanne) 9: 177, 2018.

11. Ji X, Wu Y, Yan J, Mehrens J, Yang H, DeLucia M, Hao C, Gronenborn AM, Skowronski J, Ahn J and Xiong Y: Mechanism of allosteric activation of SAMHD1 by dGTP. Nat Struct Mol Biol 20: 1304-1309, 2013.

12. Franzolin E, Pontarin G, Rampazzo C, Miazzi C, Ferraro P, Palumbo E, Reichard P and Bianchi V: The deoxynucleotide triphosphohydrolase SAMHD1 is a major regulator of DNA precursor pools in mammalian cells. Proc Natl Acad Sci USA 110: 14272-14277, 2013 
13. Clifford R, Louis T, Robbe P, Ackroyd S, Burns A, Timbs AT, Wright Colopy G, Dreau H, Sigaux F, et al: SAMHD1 is mutated recurrently in chronic lymphocytic leukemia and is involved in response to DNA damage. Blood 123: 1021-1031, 2014.

14. Wang JL, Lu FZ, Shen XY, Wu Y and Zhao LT: SAMHD1 is down regulated in lung cancer by methylation and inhibits tumor cell proliferation. Biochem Biophys Res Commun 455: 229-233, 2014.

15. Rentoft M, Lindell K, Tran P, Chabes AL, Buckland RJ, Watt DL, Marjavaara L, Nilsson AK, Melin B, Trygg J, et al: Heterozygous colon cancer-associated mutations of SAMHD1 have functional significance. Proc Natl Acad Sci USA 113: 4723-4728, 2016.

16. Lee EJ, Seo JH, Park JH, Vo TTL, An S, Bae SJ, Le H, Lee HS, Wee HJ, Lee D, et al: SAMHD1 acetylation enhances its deoxynucleotide triphosphohydrolase activity and promotes cancer cell proliferation. Oncotarget 8: 68517-68529, 2017.

17. Tramentozzi E, Ferraro P, Hossain M, Stillman B, Bianchi V and Pontarin G: The dNTP triphosphohydrolase activity of SAMHD1 persists during S-phase when the enzyme is phosphorylated at T592. Cell Cycle 17: 1102-1114, 2018

18. Coquel F, Silva MJ, Técher H, Zadorozhny K, Sharma S, Nieminuszczy J, Mettling C, Dardillac E, Barthe A Schmitz AL, et al: SAMHD1 acts at stalled replication forks to prevent interferon induction. Nature 557: 57-61, 2018.

19. Zhao K, Du J, Han X, Goodier JL, Li P, Zhou X, Wei W, Evans SL, Li L, Zhang W, et al: Modulation of LINE-1 and Alu/SVA retrotransposition by Aicardi-Goutieres syndrome-related SAMHD1. Cell Rep 4: 1108-1115, 2013.

20. Gao W, Li G, Bian X, Rui Y, Zhai C, Liu P, Su J, Wang H, Zhu C, Du Y, et al: Defective modulation of LINE-1 retrotransposition by cancer-associated SAMHD1 mutants. Biochem Biophys Res Commun 519: 213-219, 2019.

21. Herold N, Rudd SG,Ljungblad L, Sanjiv K, Myrberg IH, Paulin CB, Heshmati Y, Hagenkort A, Kutzner J, Page BD, et al: Targeting SAMHD1 with the Vpx protein to improve cytarabine therapy for hematological malignancies. Nat Med 23: 256-263, 2017.

22. Herold N, Rudd SG, Sanjiv K, Kutzner J, Bladh J, Paulin CBJ, Helleday T, Henter JI and Schaller T: SAMHD1 protects cancer cells from various nucleoside-based antimetabolites. Cell Cycle 16: 1029-1038, 2017.

23. de Silva S, Hoy H, Hake TS, Wong HK, Porcu P and Wu L: Promoter methylation regulates SAMHD1 gene expression in human CD4 ${ }^{+}$T cells. J Biol Chem 288: 9284-9292, 2013.

24. de Silva S, Wang F, Hake TS, Porcu P, Wong HK and Wu L: Downregulation of SAMHD1 expression correlates with promoter DNA methylation in Sezary syndrome patients. J Invest Dermatol 134: 562-565, 2014

25. Chen W, Cheng P, Jiang J, Ren Y, Wu D and Xue D: Epigenomic and genomic analysis of transcriptome modulation in skin cutaneous melanoma. Aging (Albany NY) 12: 12703-12725, 2020.

26. Oellerich T, Schneider C, Thomas D, Knecht KM, Buzovetsky O, Kaderali L, Schliemann C, Bohnenberger H, Angenendt L, Hartmann W, et al: Selective inactivation of hypomethylating agents by SAMHD1 provides a rationale for therapeutic stratification in AML. Nat Commun 10: 3475, 2019.

27. White TE, Brandariz-Nuñez A, Valle-Casuso JC, Amie S, Nguyen LA, Kim B, Tuzova M and Diaz-Griffero F: The retroviral restriction ability of SAMHD1, but not its deoxynucleotide triphosphohydrolase activity, is regulated by phosphorylation. Cell Host Microbe 13: 441-451, 2013.

28. Welbourn S, Dutta SM, Semmes OJ and Strebel K: Restriction of virus infection but not catalytic dNTPase activity is regulated by phosphorylation of SAMHD1. J Virol 87: 11516-11524, 2013.

29. Hochegger H, Takeda S and Hunt T: Cyclin-dependent kinases and cell-cycle transitions: Does one fit all? Nat Rev Mol Cell Biol 9: 910-916, 2008

30. Takeda DY, Wohlschlegel JA and Dutta A: A bipartite substrate recognition motif for cyclin-dependent kinases. J Biol Chem 276 1993-1997, 2001

31. Cribier A, Descours B, Valadão AL, Laguette N and Benkirane M: Phosphorylation of SAMHD1 by cyclin A2/CDK1 regulates its restriction activity toward HIV-1. Cell Rep 3: 1036-1043, 2013.

32. Kretschmer S, Wolf C, König N, Staroske W, Guck J, Häusler M, Luksch H, Nguyen LA, Kim B, Alexopoulou D, et al: SAMHD1 prevents autoimmunity by maintaining genome stability. Ann Rheum Dis 74: e17, 2015

33. Yan J, Hao C, DeLucia M, Swanson S, Florens L, Washburn MP, Ahn J and Skowronski J: CyclinA2-cyclin-dependent kinase regulates SAMHD1 protein phosphohydrolase domain. J Biol Chem 290: 13279-13292, 2015
34. Hu J, Qiao M, Chen Y, Tang H, Zhang W, Tang D, Pi S, Dai J, Tang N, Huang A and Hu Y: Cyclin E2-CDK2 mediates SAMHD1 phosphorylation to abrogate its restriction of HBV replication in hepatoma cells. FEBS Lett 592: 1893-1904, 2018.

35. Pauls E, Badia R, Torres-Torronteras J, Ruiz A, Permanyer M, Riveira-Muñoz E, Clotet B, Marti R, Ballana E and Esté JA: Palbociclib, a selective inhibitor of cyclin-dependent kinase $4 / 6$, blocks HIV-1 reverse transcription through the control of sterile alpha motif and HD domain-containing protein-1 (SAMHD1) activity. AIDS 28: 2213-2222, 2014.

36. Badia R, Angulo G, Riveira-Muñoz E, Pujantell M, Puig T, Ramirez C, Torres-Torronteras J, Martí R, Pauls E, Clotet B, et al: Inhibition of herpes simplex virus type 1 by the CDK6 inhibitor PD-0332991 (palbociclib) through the control of SAMHD1. J Antimicrob Chemother 71: 387-394, 2016.

37. Allouch A, David A, Amie SM, Lahouassa H, Chartier L, Margottin-Goguet F, Barré-Sinoussi F, Kim B, Sáez-Cirión A and Pancino G: p21-mediated RNR2 repression restricts HIV-1 replication in macrophages by inhibiting dNTP biosynthesis pathway. Proc Natl Acad Sci USA 110: E3997-E4006, 2013.

38. Pauls E, Ruiz A, Riveira-Muñoz E, Permanyer M, Badia R, Clotet B, Keppler OT, Ballana E and Este JA: p21 regulates the HIV-1 restriction factor SAMHD1. Proc Natl Acad Sci USA 111: E1322-E1324, 2014.

39. Osei Kuffour E, Schott K, Jaguva Vasudevan AA, Holler J, Schulz WA, Lang PA, Lang KS, Kim B, Häussinger D, König R and Münk C: USP18 (UBP43) abrogates p21-mediated inhibition of HIV-1. J Virol 92: e00592-18, 2018.

40. Schott K, Fuchs NV, Derua R, Mahboubi B, Schnellbächer E, Seifried J, Tondera C, Schmitz H, Shepard C, Brandariz-Nuñez A, et al: Dephosphorylation of the HIV-1 restriction factor SAMHD1 is mediated by PP2A-B55alpha holoenzymes during mitotic exit. Nat Commun 9: 2227, 2018

41. Kueck T, Cassella E, Holler J, Kim B and Bieniasz PD: The aryl hydrocarbon receptor and interferon gamma generate antiviral states via transcriptional repression. Elife 7: e38867, 2018.

42. Bonifati S, Daly MB, St Gelais C, Kim SH, Hollenbaugh JA, Shepard C, Kennedy EM, Kim DH, Schinazi RF, Kim B and Wu L: SAMHD1 controls cell cycle status, apoptosis and HIV-1 infection in monocytic THP-1 cells. Virology 495: 92-100, 2016.

43. Kodigepalli KM, Li M, Liu SL and Wu L: Exogenous expression of SAMHD1 inhibits proliferation and induces apoptosis in cutaneous T-cell lymphoma-derived HuT78 cells. Cell Cycle 16 179-188, 2017.

44. Welbourn S, Miyagi E, White TE, Diaz-Griffero F and Strebel K: Identification and characterization of naturally occurring splice variants of SAMHD1. Retrovirology 9: 86, 2012.

45. Kodigepalli $\mathrm{KM}$, Bonifati $\mathrm{S}$, Tirumuru $\mathrm{N}$ and $\mathrm{Wu} \mathrm{L}$ SAMHD1 modulates in vitro proliferation of acute myeloid leukemia-derived THP-1 cells through the PI3K-Akt-p27 axis. Cell Cycle 17: 1124-1137, 2018.

46. Feng Q, Moran JV, Kazazian HH Jr and Boeke JD: Human L1 retrotransposon encodes a conserved endonuclease required for retrotransposition. Cell 87: 905-916, 1996.

47. Burns KH: Transposable elements in cancer. Nat Rev Cancer 17: 415-424, 2017.

48. White TE, Brandariz-Nuñez A, Valle-Casuso JC, Knowlton C, Kim B, Sawyer SL and Diaz-Griffero F: Effects of human SAMHD1 polymorphisms on HIV-1 susceptibility. Virology 460-461: 34-44, 2014

49. White TE, Brandariz-Nuñez A, Valle-Casuso JC, Amie S, Nguyen L, Kim B, Brojatsch J and Diaz-Griffero F: Contribution of SAM and HD domains to retroviral restriction mediated by human SAMHD1. Virology 436: 81-90, 2013

50. Du J, Peng Y, Wang S, Hou J, Wang Y, Sun T and Zhao K: Nucleocytoplasmic shuttling of SAMHD1 is important for LINE-1 suppression. Biochem Biophys Res Commun 510: 551-557, 2019.

51. Herrmann A, Wittmann S, Thomas D, Shepard CN, Kim B, Ferreirós N and Gramberg T: The SAMHD1-mediated block of LINE-1 retroelements is regulated by phosphorylation. Mobile DNA 9: 11, 2018.

52. Hu S, Li J, Xu F, Mei S, Le Duff Y, Yin L, Pang X, Cen S, Jin Q, Liang $C$ and Guo F: SAMHD1 inhibits LINE-1 retrotransposition by promoting stress granule formation. PLoS Genetics 11: e1005367, 2015.

53. Håkansson P, Hofer A and Thelander L: Regulation of mammalian ribonucleotide reduction and dNTP pools after DNA damage and in resting cells. J Biol Chem 281: 7834-7841, 2006. 
54. Jauregui $P$ and Landau NR: DNA damage induces a SAMHD1-mediated block to the infection of macrophages by HIV-1. Sci Rep 8: 4153, 2018.

55. Daddacha W, Koyen AE, Bastien AJ, Head PE, Dhere VR, Nabeta GN, Connolly EC, Werner E, Madden MZ, Daly MB, et al: SAMHD1 promotes DNA end resection to facilitate DNA repair by homologous recombination. Cell Rep 20: 1921-1935, 2017.

56. Ballana E, Badia R, Terradas G, Torres-Torronteras J, Ruiz A, Pauls E, Riveira-Muñoz E, Clotet B, Martí R and Esté JA: SAMHD1 specifically affects the antiviral potency of thymidine analog HIV reverse transcriptase inhibitors. Antimicrob Agents Chemother 58: 4804-4813, 2014.

57. Guièze R, Robbe P, Clifford R, de Guibert S, Pereira B, Timbs A, Dilhuydy MS, Cabes M, Ysebaert L, Burns A, et al: Presence of multiple recurrent mutations confers poor trial outcome of relapsed/refractory CLL. Blood 126: 2110-2117, 2015.

58. Grant S: Ara-C: Cellular and molecular pharmacology. Adv Cancer Res 72: 197-233, 1998

59. Schneider C, Oellerich T, Baldauf HM, Schwarz SM, Thomas D, Flick R, Bohnenberger H, Kaderali L, Stegmann L, Cremer A, et al: SAMHD1 is a biomarker for cytarabine response and a therapeutic target in acute myeloid leukemia. Nat Med 23: 250-255, 2017.

60. Arnold LH, Kunzelmann S, Webb MR and Taylor IA: A continuous enzyme-coupled assay for triphosphohydrolase activity of HIV-1 restriction factor SAMHD1. Antimicrob Agents Chemother 59: 186-192, 2015.

61. Knecht KM, Buzovetsky O, Schneider C, Thomas D, Srikanth V, Kaderali L, Tofoleanu F, Reiss K, Ferreirós N, Geisslinger G, et al: The structural basis for cancer drug interactions with the catalytic and allosteric sites of SAMHD1. Proc Natl Acad Sci USA 115: E10022-E10031, 2018

62. Rassidakis GZ, Herold N, Myrberg IH, Tsesmetzis N, Rudd SG Henter JI, Schaller T, Ng SB, Chng WJ, Yan B, et al: Low-level expression of SAMHD1 in acute myeloid leukemia (AML) blasts correlates with improved outcome upon consolidation chemotherapy with high-dose cytarabine-based regimens. Blood Cancer J 8: 98, 2018.

63. Wang YT, Yuan B, Chen HD, Xu L, Tian YN, Zhang A He JX and Miao ZH: Acquired resistance of phosphatase and tensin homolog-deficient cells to poly(ADP-ribose) polymerase inhibitor and Ara-C mediated by 53BP1 loss and SAMHD1 overexpression. Cancer Sci 109: 821-831, 2017.

64. Rudd SG, Tsesmetzis N, Sanjiv K, Paulin CB, Sandhow L, Kutzner J, Hed Myrberg I, Bunten SS, Axelsson H, Zhang SM, et al: Ribonucleotide reductase inhibitors suppress SAMHD1 ara-CTPase activity enhancing cytarabine efficacy. EMBO Mol Med 12: e10419, 2020.

65. Hollenbaugh JA, Shelton J, Tao S, Amiralaei S, Liu P, Lu X, Goetze RW, Zhou L, Nettles JH, Schinazi RF and Kim B Substrates and Inhibitors of SAMHD1. PLoS One 12: e0169052, 2017.

66. Jones S, Zhang X, Parsons DW, Lin JC, Leary RJ, Angenendt P, Mankoo P, Carter H, Kamiyama H, Jimeno A, et al: Core signaling pathways in human pancreatic cancers revealed by global genomic analyses. Science 321: 1801-1806, 2008.

67. Kohnken R, Kodigepalli KM and Wu L: Regulation of deoxynucleotide metabolism in cancer: Novel mechanisms and therapeutic implications. Mol Cancer 14: 176, 2015.

68. James CD, Prabhakar AT, Otoa R, Evans MR, Wang X, Bristol ML, Zhang K, Li R and Morgan IM: SAMHD1 regulates human papillomavirus 16 -induced cell proliferation and viral replication during differentiation of keratinocytes. mSphere 4 : e00448-19, 2019.
69. Stanland LJ and Luftig MA: The role of EBV-induced hypermethylation in gastric cancer tumorigenesis. Viruses 12: 1222, 2020.

70. Cruz-Gregorio A, Aranda-Rivera AK and Pedraza-Chaverri J: Human papillomavirus-related cancers and mitochondria. Virus Res 286: 198016, 2020.

71. Cabello-Lobato MJ, Wang S and Schmidt CK: SAMHD1 sheds moonlight on DNA double-strand break repair. Trends Genet 33: 895-897, 2017.

72. Seamon KJ and Stivers JT: A high-throughput enzyme-coupled assay for SAMHD1 dNTPase. J Biomol Screen 20: 801-809, 2015.

73. Mauney $\mathrm{CH}$, Perrino FW and Hollis T: Identification of inhibitor of the dNTP triphosphohydrolase SAMHD1 using a novel and direct high-throughput assay. Biochemistry 57: 6624-6636, 2018.

74. Jiang H, Li C and Liu Z, Shengjing Hospital; Hu: Expression and relationship of SAMHD1 with other apoptotic and autophagic genes in acute myeloid leukemia patients. Acta Haematol 143: $51-59,2020$

75. Kodigepalli KM, Li M, Bonifati S, Panfil AR, Green PL, Liu SL and Wu L: SAMHD1 inhibits epithelial cell transformation in vitro and affects leukemia development in xenograft mice. Cell Cycle 17: 2564-2576, 2018.

76. Herold N, Rudd SG, Sanjiv K, Kutzner J, Myrberg IH, Paulin CBJ, Olsen TK, Helleday T, Henter JI and Schaller T: With me or against me: Tumor suppressor and drug resistance activities of SAMHD1. Exp Hematol 52: 32-39, 2017.

77. Rothenburger T, McLaughlin KM, Herold T, Schneider C, Oellerich T, Rothweiler F, Feber A, Fenton TR, Wass MN, Keppler OT, et al: SAMHD1 is a key regulator of the lineage-specific response of acute lymphoblastic leukaemias to nelarabine. Commun Biol 3: 324, 2020.

78. Yang CA, Huang HY, Chang YS, Lin CL, Lai IL and Chang JG: DNA-sensing and nuclease gene expressions as markers for colorectal cancer progression. Oncology 92: 115-124, 2017.

79. Shang Z, Qian L, Liu S, Niu X, Qiao Z, Sun Y, Zhang Y, Fan LY, Guan X, Cao CX and Xiao H: Graphene oxide-facilitated comprehensive analysis of cellular nucleic acid binding proteins for lung cancer. ACS Appl Mater Interfaces 10: 17756-17770, 2018.

80. Shi Y, Lv G, Chu Z, Piao L, Liu X, Wang T, Jiang Y and Zhang P: Identification of natural splice variants of SAMHD1 in virus-infected HCC. Oncol Rep 31: 687-692, 2014.

81. Merati M, Buethe DJ, Cooper KD, Honda KS, Wang H and Gerstenblith MR: Aggressive CD8(+) epidermotropic cutaneous T-cell lymphoma associated with homozygous mutation in SAMHD1. JAAD Case Rep 1: 227-229, 2015.

82. Amin NA, Seymour E, Saiya-Cork K, Parkin B, Shedden K and Malek SN: A quantitative analysis of subclonal and clonal gene mutations before and after therapy in chronic lymphocytic leukemia. Clin Cancer Res 22: 4525-4535, 2016.

83. Zhu KW, Chen P, Zhang DY, Yan H, Liu H, Cen LN, Liu YL, Cao S, Zhou G, Zeng H, et al: Association of genetic polymorphisms in genes involved in Ara-C and dNTP metabolism pathway with chemosensitivity and prognosis of adult acute myeloid leukemia (AML). J Transl Med 16: 90, 2018.

This work is licensed under a Creative Commons Attribution-NonCommercial-NoDerivatives 4.0 International (CC BY-NC-ND 4.0) License. 